[Agr. Biol. Chem., Vol. 36, No. 10, p. $1777 \sim 1782,1972]$

\title{
Isolation and Structure of a New Steroid, Asterosapogenine I, from Asterosaponins $\mathrm{A}$ and $\mathrm{B}^{\dagger}$
}

\author{
By Susumu Ikegami, Yuji KamiYa and Saburo Tamura \\ Department of Agricultural Chemistry, The University \\ of Tokyo, Bunkyo-ku, Tokyo \\ Received February 29, 1972
}

\begin{abstract}
A new steroid, asterosapogenine I, was isolated as the main component in acid hydrolyzates of asterosaponins $\mathrm{A}$ and $\mathrm{B}$. The structure of the compound was assigned to be $3,3,6 \alpha$-dihydroxy-5 $\alpha$-pregn-9(11)-en-20-one.
\end{abstract}

The occurrence of toxic saponins in starfish has been known since some years ago. ${ }^{11}$ In 1964 Yasumoto et al. ${ }^{21}$ isolated a mixture of six saponins from the Japanese starfish, Asterias amurensis, and named the major two components asterosaponins $\mathrm{A}$ and $\mathrm{B}$. They hydrolyzed asterosaponin $\mathrm{A}$ with hydrochloric acid to afford two moles each of D-fucose and $D$-quinovose together with one mole of sulfuric acid. Similar treatment of asterosaponin B yielded two moles of D-quinovose and one mole each of D-fucose, D-galactose, D-xylose and sulfuric acid. Further they separated two aglycones from the both hydrolyzates and assigned the common formula $\mathrm{C}_{22} \mathrm{H}_{34} \mathrm{O}_{3}$ to them. ${ }^{3}$

In succession to these studies, we subjected asterosaponins A and B to acid hydrolysis, which afforded a mixture of steroidal aglycones being composed of $21 \sim 28$ carbons and $2 \sim 3$ oxygens. In this paper we wish to present details of our experimental results leading to structural elucidation of a new steroid, now called asterosapogenine I, which was isolated as the main component of the mixture.

A crude mixture of asterosaponins was hydrolyzed with an ethanolic solution of $p$ toluenesulfonic acid. The hydrolyzate was

Studies on Asterosaponins. Part I. diluted with water and extracted with chloroform. Evaporation of the solvent yielded a gum, which was acetylated with acetic anhydride in pyridine. A mixture of acetylated aglycones thus obtained was chromatographed on a silica gel column using a solvent system of benzene-ethyl acetate increasing successively the ratio of the latter. Elution with a solvent containing $5 \sim 10 \%$ ethyl acetate gave a mixture of aglycone acetates with molecular weights ranging from 484 to 526 (Fraction 1). Twenty per cent ethyl acetate afforded a component with a molecular weight of 416 (Fraction 2). Gas-liquid chromatography (GLC) revealed that Fraction 1 contained several components. On the other hand, Fraction 2 was found to be almost homogeneous. The same results were obtained when purified asterosaponin A or B was hydrolyzed in place of the crude mixture. Even by mass spectrometric survey, however, the aglycone with the molecular formula $\mathrm{C}_{22} \mathrm{H}_{34} \mathrm{O}_{3}$ reported by Yasumoto et al. $^{3}$ has never been detected in any chromatographic fractions from the hydrolyzate with $p$-toluenesulfonic or hydrochloric acid.

Then, the experiment was carried out with Fraction 2. The main aglycone acetate in the fraction was treated with $5 \%$ methanolic $\mathrm{KOH}$ to regenerate the free aglycone (1). 1 was subjected to preparative thin-layer chro- 


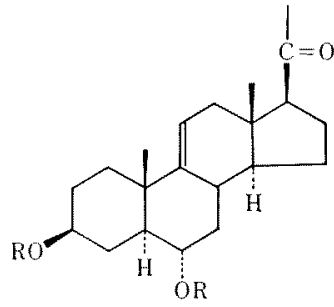

$1(\mathrm{R}=\mathrm{H})$

$2(\mathrm{R}=\mathrm{Ac})$

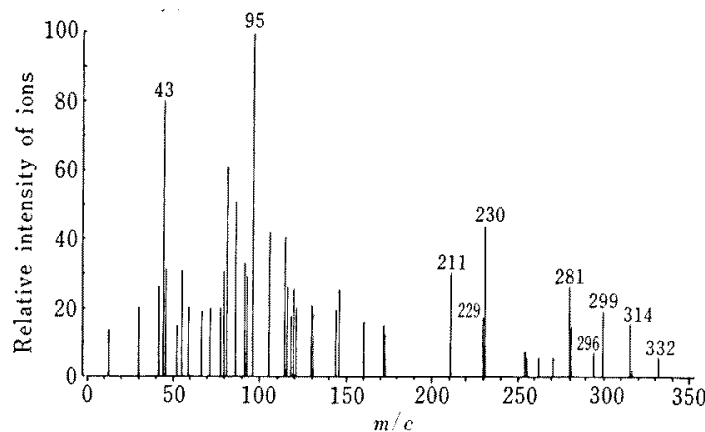

Fig. 1. Mass Spectrum of Asterosapogenine I (1).

matography (TLC, Kieselgel $\mathrm{GF}_{254}$ ) using benzene-acetone $(2: 1, \quad \mathrm{v} / \mathrm{v}) . \quad \mathrm{C}_{21} \mathrm{H}_{32} \mathrm{O}_{3}, \mathrm{mp}$ $157 \sim 160^{\circ} \mathrm{C}, \quad[\alpha]_{D}^{23} \quad 65.2^{\circ} \quad\left(c=1.08, \quad \mathrm{CHCl}_{3}\right)$. 1 showed no absorption maximum above 210 $\mathrm{m} \mu$ suggesting the absence of a conjugated diene or carbonyl system. The mass spectrum (Fig. 1) showed peaks at $m / e: 332\left(\mathrm{M}^{+}\right), 314$ $\left(\mathrm{M}^{+}-\mathrm{H}_{2} \mathrm{O}\right), 299\left(\mathrm{M}^{+}-\mathrm{H}_{2} \mathrm{O}-\mathrm{CH}_{3}\right), 296\left(\mathrm{M}^{+}\right.$ $\left.\mathrm{H}_{2} \mathrm{O} \times 2\right), 281 \quad\left(\mathrm{M}^{+}-\mathrm{H}_{2} \mathrm{O} \times 2-\mathrm{CH}_{3}\right), 229 \sim 230$ (ring-D fission and dehydration), $95\left(\mathrm{C}_{7} \mathrm{H}_{11}\right)$ and $43\left(\mathrm{CH}_{3} \mathrm{CO}\right)$, which suggested that 1 is a steroid containing an acetyl at $\mathrm{C}-17$ and two hydroxyls and a double bond on the ring structure. This assignment was further supported by the NMR spectrum (Fig. 2), which showed the signals of two tertiary methyls at o 0.59 and 0.97 (3H each, singlet), an acetyl at $\delta 2.17(3 \mathrm{H}$, singlet), an allylic methylene at $\delta 2.27(2 \mathrm{H}$, multiplet), two hydroxyls at $\delta 2.72$ ( $2 \mathrm{H}$, broad singlet), a methine adjacent to carbonyl at $\delta 2.63(1 \mathrm{H}$, triplet), two secondary

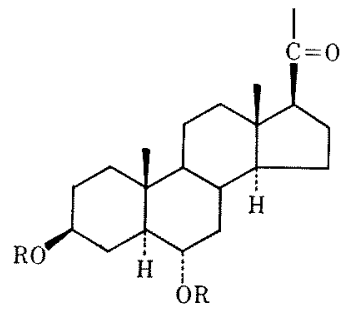

$4(\mathrm{R}=\mathrm{Ac})$

$5(\mathrm{R}=\mathrm{H})$

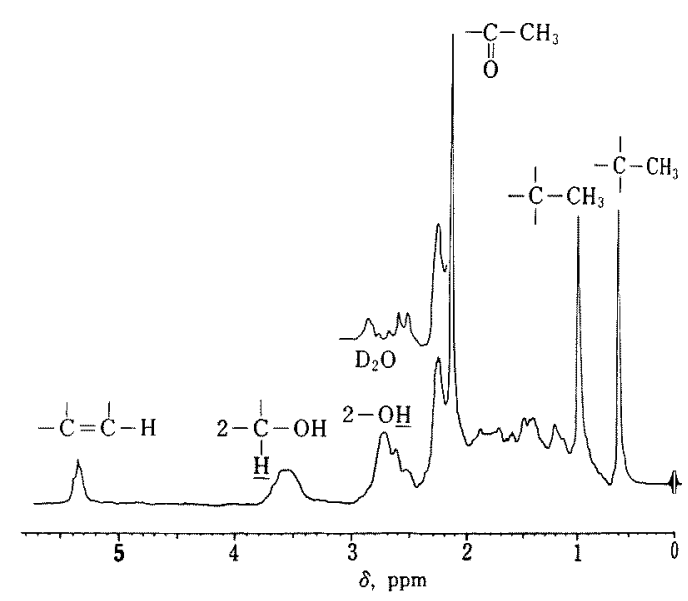

FIG. 2. NMR Spectrum of Asterosapogenine I (1).

carbinol methines at $\delta 3.55(2 \mathrm{H}$, broad multiplet) and an olefinic proton at $\delta 5.35(1 \mathrm{H}$, multiplet). The ORD curve of 1 showed a positive Cotton effect suggesting that the acetyl group at $\mathrm{C}-17$ possesses $\beta$ configuration. $^{4)}$ Treatment of 1 with acetic anhydride in pyridine afforded a diacetate $2, \mathrm{C}_{25} \mathrm{H}_{36} \mathrm{O}_{5}$, $[\alpha]_{\mathrm{D}}^{23} \quad 60.3^{\circ}\left(c=1.69, \mathrm{CHCl}_{3}\right)$. In the NMR spectrum of 2 (Fig. 3), 2H doublet at $\delta 2.28$ due to an allylic methylene coupled solely with $1 \mathrm{H}$ triplet of an olefinic proton. Therefore, the trisubstituted double bond is located at the $9: 11$ position.

Oxidation of $\mathbf{1}$ with chromium trioxide in pyridine gave a triketone. $3, \mathrm{C}_{21} \mathrm{H}_{28} \mathrm{O}_{3}$, mp $194 \sim 196^{\circ} \mathrm{C}, \quad[\alpha]_{\mathrm{D}}^{25} \quad 21.6^{\circ} \quad\left(c=1.20, \mathrm{CHCl}_{3}\right)$. The IR spectrum (Fig. 4) indicated that the 


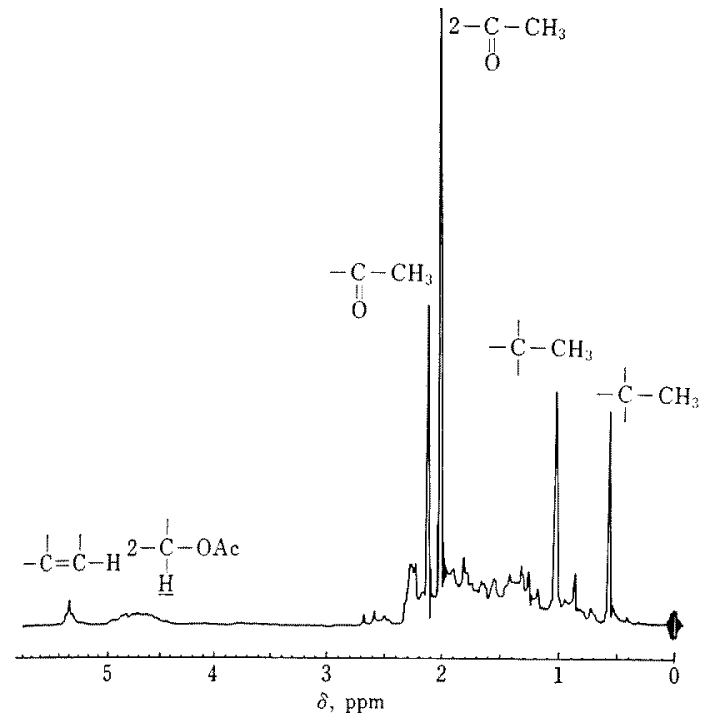

Fio. 3. NMR Spectrum of Diacetate of Asterosapogenine I (2).

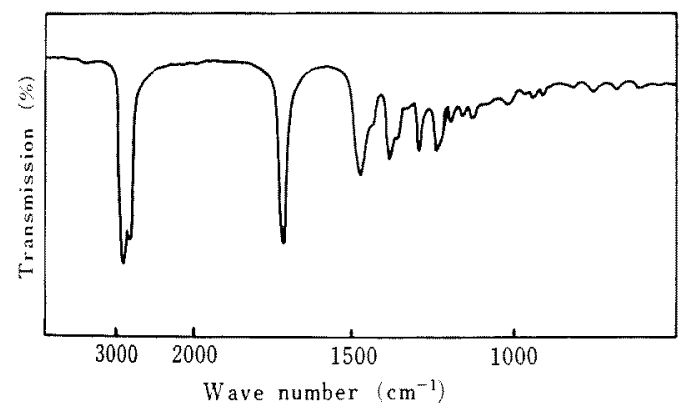

FIG. 4. IR Spectrum of Triketone 3 .

newly formed ketones $\left(1700 \mathrm{~cm}^{-1}\right)$ are contained in the six-membered rings. Transparence in the UV region suggested the absence of an $\alpha, \beta$-unsaturated ketone in 3 . Its NMR spectrum (Fig. 5) exhibited two tertiary methyls at $\delta 0.62$ and 1.11 (3H each, singlet), an acetyl at $\delta 2.15(3 \mathrm{H}$, singlet $)$ and an olefinic proton at $\delta 5.63(1 \mathrm{H}$, triplet, $J=4 \mathrm{cps})$. A decoupling experiment showed that the olefinic proton couples with an doublet at $\delta 2.38$. No signals corresponding to methylene or methine protons between 1,3-diketones or $\beta, \gamma$-unsaturated ketone were observed. From the considera-

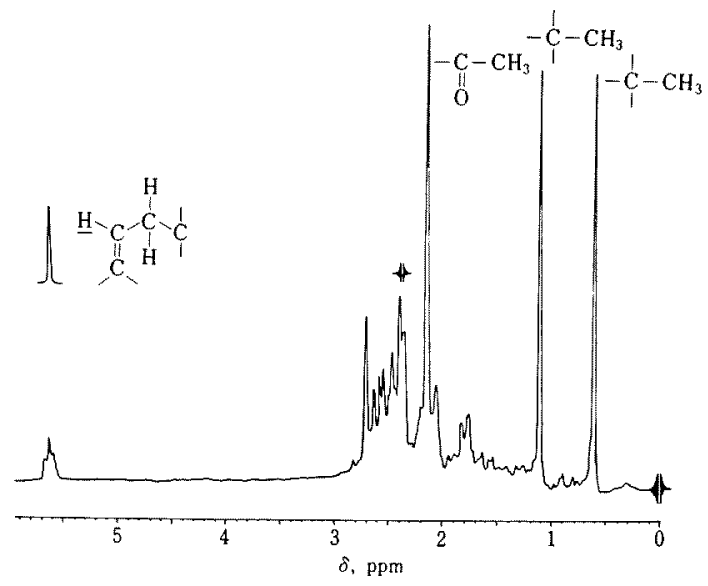

FIG. 5. NMR Spectrum of Triketone 3 .

tion on the fact that ordinary natural steroids contain a hydroxyl group at C-3, we tentatively fixed the two carbonyl groups in the ring structure of 3 at $\mathrm{C}-3$ and $\mathrm{C}-6$.

The signal at $\delta 3.55$ corresponding to two carbinol methines in $\mathbf{1}$ is only understandable by assuming that configuration of $\mathrm{C}-3$ and C -6 are equatorial, i.e. $3 \beta$ and $6 \alpha .^{5}$

NMR spectral data on the series of compounds $\mathbf{1} \sim \mathbf{3}$ accord with the A/B-trans-ring junction, rather than the $\mathrm{A} / \mathrm{B}$-cis-junction by comparing chemical shifts of two tertiary methyls at $\mathrm{C}-18$ and $\mathrm{C}-19$ of these compounds with the values calculated according to the method of Zürcher ${ }^{6}$ (Table I). Therefore, the structure of 1 would be $3 \beta, 6 \alpha$-dihydroxy-

Table I. Chemical Shifts of the C-18 and C-19 Methyl Groups in $1 \sim 5(\delta$, ppm Downfield from Internal TMS)

\begin{tabular}{ccccc}
\hline \multirow{2}{*}{ Compound } & \multicolumn{2}{c}{ C-18 Methyl } & \multicolumn{2}{c}{ C-19 Methyl } \\
\cline { 2 - 5 } & Obsd. & Calcd. & Obsd. & Calcd. \\
\hline $\mathbf{1}$ & 0.59 & 0.56 & 0.97 & 0.95 \\
$\mathbf{2}$ & 0.57 & 0.56 & 1.03 & 1.02 \\
$\mathbf{3}$ & 0.62 & 0.60 & 1.11 & 1.12 \\
$\mathbf{4}$ & 0.63 & 0.61 & 0.88 & 0.87 \\
$\mathbf{5}$ & 0.61 & 0.62 & 0.82 & 0.81 \\
\hline
\end{tabular}


$5 \alpha$-pregn-9(11)-en-20-one.

Catalytic hydrogenation of $\mathbf{2}$ in acetic acid over platinic oxide, followed by oxidation with chromium trioxide in pyridine, gave a dihydro-diacetate 4. Molecular weight 418, $[\alpha]_{\mathrm{D}}^{25} 46.1^{\circ}\left(c=2.31, \mathrm{CHCl}_{3}\right)$. On hydrolysis with $5 \%$ methanolic $\mathrm{KOH}, 4$ afforded the corresponding diol 5, $\mathrm{C}_{21} \mathrm{H}_{34} \mathrm{O}_{3}, \quad$ mp 183 $185^{\circ} \mathrm{C},[\alpha]_{D}^{25} 50.7^{\circ}\left(c=1.26, \mathrm{CHCl}_{3}\right)$. In its mass spectrum, all of the peaks associated with 1 were observed, though they were shifted to higher values by two mass-units. Furthermore, disappearance of the 9:11 double bond was confirmed by its NMR spectrum.

Finally, the structure of $\mathbf{1}$ was established through the synthesis of 2,4-dinitrophenylhydrazone of $\mathbf{5}$ in the following procedure. 2,4-Dinitrophenylhydrazone of pregnenolone was treated with diborane to afford a dialkylborane, which was subsequently oxidized with basic hydrogen peroxide. Since the Brown borohydration of $\Delta^{5}$ steroids occurs in a cis manner from the less hindered side of the double bond, ") the product should be the hydrazone of $3 \beta, 6 \alpha$-dihydroxy- $5 \alpha$-pregnane20-one. Expectedly, its mp, GLC, TLC, IR, NMR and mass spectrometric data showed complete identity with those of the 2,4-dinitrophenylhydrazone derived from the natural 5. Accordingly, the structure of $\mathbf{1}$ has been unambiguously determined to be $3 \beta, 6 \alpha$ dihydroxy-5a-pregn-9(11)-en-20-one.

Just at the time when we have finished the structure elucidation of asterosapogenine $I$, we noticed the report of Turner et al. ${ }^{8}$ who established quite independently the structures of the main aglycones from the Marthasterias glacialis saponin as $3 \beta, 6 \alpha$-dihydroxy- $5 \alpha$-cholesta-9(11). 24-diene-23-one(marthasterone) and its 24,25 -dihydro derivative. It is very interesting that asterosapogenine I and marthasterone possess the identical ring structure in spite of the difference in physical and chemical natures of the original saponins. ${ }^{91}$

\section{EXPERIMENTAL}

Mps were determined on a microscope hot stage and were reported uncorrected. Optical rotations were measured in a JASCO DIP-S polarimeter. IR spectra were obtained with a JASCO IR-S spectrometer. NMR spectra were recorded on a JEOL$\mathrm{JNM}-4 \mathrm{H}$ spectrometer at $100 \mathrm{Mc}$ in $\mathrm{ca} .100 \% \mathrm{CDCl}_{3}$ solutions with tetramethylsilane as an internal standard. Mass spectra were measured with a Hitachi RMU-6L mass spectrometer operating with an ionization energy (70eV). High resolution mass spectra were obtained with a Hitachi RMH-2 as direct probe sample using an ionizing voltage of $70 \mathrm{eV}$. ORD spectra were recorded on a JASCO ORD/UV-5 spectrometer using EtOH as a solvent. GLC analyses were performed on a Hitachi K-52 using columns packed with $3 \%$ OV-1 on Chromosorb at $230^{\circ} \mathrm{C}$. TLC were carried out with silica gel $\mathrm{GF}_{254}$ (Merck) plates of $0.25 \mathrm{~mm}$ thickness, which were developed with solvent systems of benzene-ethyl acetate $(5: 1, v / v)(A)$, benzene-acetone $(5: 1, \mathrm{v} / \mathrm{v})(\mathrm{B})$, benzene-acetone $(2: 1$, $\mathrm{v} / \mathrm{v})(\mathrm{C})$ and benzene-acetone $(3: 2, \mathrm{v} / \mathrm{v})$ (D). Spots were detected by spraying a $10 \%(\mathrm{w} / \mathrm{v})$ solution of phosphotungustic acid in ethanol or under a UV lamp $(254 \mathrm{~m} \mu)$.

Acid hydrolysis of crude asterosaponins. A crude mixture of asterosaponins $(8.7 \mathrm{~g})$ was dissolved in ethanol $(300 \mathrm{ml})$ containing $p$-toluenesulfonic acid $(12 \mathrm{~g})$ and was heated under reflux for $65 \mathrm{hr}$. The solution was then diluted with $1200 \mathrm{ml}$ of water and extracted with chloroform. The chloroform layer was washed with saturated $\mathrm{NaHCO}_{3}$ solution and water. Evaporation of the chloroform left a brown gum $(3.4 \mathrm{~g})$, designated "crude aglycone mixture," which was found to contain at least six components on examination on TLC chromatogram. On the chromatogram developed with the solvent system $\mathrm{C}$, two components with $R f 0.39$ and $R f 0.29$ were dominant. The former showed strong UV absorption, whereas the latter did not.

Purification of crude acetates of aglycones (2). The crude aglycone mixture $(3.4 \mathrm{~g})$ was added to a mixture of acetic anhydride $(20 \mathrm{ml})$ and pyridine $(30 \mathrm{ml})$ and kept standing at room temperature overnight. The solution was poured onto ice and extracted with benzene. The benzene layer was washed with dil. $\mathrm{HCl}$ and water. Evaporation of the solvent gave a brown gum $(3.7 \mathrm{~g})$. The residue was chromatographed on a silica gel column $(2.7 \times 46 \mathrm{~cm}$, Mallinckrodt) using 
a solvent system of benzene-ethyl acetate. An eluate with $5 \%$ ethyl acetate in benzene (Fraction 1) was evaporated to give a residue $(328 \mathrm{mg}$ ). GLC of the residue gave several peaks and high resolution mass spectrometry revealed it to be a mixture of aglycones with molecular formulas, $\mathrm{C}_{33} \mathrm{H}_{50} \mathrm{O}_{5}, \quad \mathrm{C}_{32} \mathrm{H}_{48} \mathrm{O}_{5}$, $\mathrm{C}_{31} \mathrm{H}_{48} \mathrm{O}_{5}, \quad \mathrm{C}_{31} \mathrm{H}_{46} \mathrm{O}_{5}, \quad \mathrm{C}_{30} \mathrm{H}_{46} \mathrm{O}_{5}, \quad \mathrm{C}_{28} \mathrm{H}_{42} \mathrm{O}_{5}, \quad \mathrm{C}_{28} \mathrm{H}_{44} \mathrm{O}_{4}$ and $\mathrm{C}_{28} \mathrm{H}_{40} \mathrm{O}_{4}$. Evaporation of the eluate with $20 \%$ ethyl acetate in benzene (Fraction 2) gave a residue $(531 \mathrm{mg})$. By GLC it was revealed nearly homogeneous. Fraction 2 was further subjected to preparative TLC with the solvent system A. The zone at $R f 0.54$ was cut out and extracted with ethyl acetate. Evaporation of the solvent afforded an oily residue $(441 \mathrm{mg})$. $[\alpha]_{\mathrm{D}}^{23} 60.3^{\circ}\left(c=1.69, \mathrm{CHCl}_{3}\right) ;$ IR $v_{\max }^{\mathrm{Film}} \mathrm{cm}^{-1}: 1735$, $1703,1365,1250,1030,825$; MS m/e: 416, 356, 341, $296,281,271,263,255,226,211,85$ (base peak), ORD $(c=0.126$, EtOH $)[\alpha]^{25}(\mathrm{~m} / t): 527^{\circ}$ (309), $-346^{\circ}$ (278). The NMR spectrum was shown in Fig. 3.

Aglycone (I). Acetate $2(113 \mathrm{mg})$ was treated with $5 \% \mathrm{KOH}$ in $\mathrm{MeOH}(20 \mathrm{ml})$ at room temperature for $30 \mathrm{~min}$. The reaction mixture was adjusted to $\mathrm{pH} 7$ with dil. $\mathrm{HCl}$ and was extracted with ethyl acetate. Evaporation of the solvent gave a colorless powder (91 mg). mp $157 \sim 160^{\circ} \mathrm{C} ; \quad[\alpha]_{\mathrm{D}}^{23} \quad 65.2^{\circ} \quad(c=1.08$, $\mathrm{CHCl}_{3}$ ); $\mathrm{C}_{21} \mathrm{H}_{32} \mathrm{O}_{3}, \mathrm{M}^{+} 332.2363$ (required 332.2350); IR $\nu_{\mathrm{max}}^{\mathrm{xujol}} \mathrm{cm}^{-1}: 3240,1700,1040,825 ;$ ORD $(c=0.056$, EtOH) $[\alpha]^{25}(\mathrm{~m} \mu) ; \quad 1371^{\circ}(308),-1102^{\circ}$ (268). The mass and NMR spectra were shown in Figs. 1 and 2 respectively.

Triketone (3). Aglycone 1 (70.4 mg) was dissolved in pyridine $(2 \mathrm{ml})$, to which chromium trioxide $(100 \mathrm{mg})$ in pyridine $(1 \mathrm{ml})$ was added. The reaction mixture was left stand overnight at room temperature. Then, the solution was diluted with water and extracted repeatedly with benzene. The combined extracts were washed with dil. $\mathrm{HCl}$ and water. Evaporation of the solvent gave a residue, which was purified by preparative TLC with the solvent system of $C$. The zone at $R f 0.61$ was extracted with chloroform-methanol $(1: 1, v / v)$. Evaporation of the solvents gave colorless needles. $\mathrm{mp} 194 \sim 196.5^{\circ} \mathrm{C} ;[\alpha]_{\mathrm{D}}^{25} 21.6^{\circ}\left(c=1.2, \mathrm{CHCl}_{3}\right)$; $\mathrm{C}_{21} \mathrm{H}_{28} \mathrm{O}_{3} \mathrm{M}^{+} 328.2053$ (required 328.2037); $\mathrm{MS}$ m/e : $328,313,295,285,271,267,255,243$ (base peak), 225, 197; ORD $\left(c=0.0139\right.$, EtOH $[\alpha]^{25}(\mathrm{~m} / \mathrm{l}): 1800^{\circ}$ (305), $-2073^{\circ}$ (264). The IR and NMR spectra were shown in Figs. 4 and 5 respectively.

Hydrogenation of diacetate (2). Diacetate 2 $(24.8 \mathrm{mg}$ ) was dissolved in acetic acid $(5 \mathrm{ml})$, to which platinic oxide $(15 \mathrm{mg})$ catalyst in acetic acid $(10 \mathrm{ml})$ was added. Hydrogenation was conducted at atmospheric pressure overnight. The reaction mixture was filtered and the catalyst was washed with ethyl acetate. The combined filtrates were diluted with water and repeatedly extracted with ethyl acetate. The extracts were washed with saturated $\mathrm{NaHCO}_{3}$ solution and water, dried and evaporated. The residue was purified by preparative TLC with the solvent system of $\mathrm{A}$. The zone at $R f 0.60$ was cut out and extracted with ethyl acetate. Evaporation of the solvent gave an colorless oil (24.2 mg). $\mathrm{C}_{25} \mathrm{H}_{40} \mathrm{O}_{5}$; IR $v_{\max }^{\mathrm{Nujol}} \mathrm{cm}^{-1}: \quad 3520,1740,1450,1375,1250,1030$; MS m/e: 420, 402, 374, 369, 345, 342, 327, 313, 300, $285,282,274,255,214$ (base peak); NMR $0: 0.75$ $(3 \mathrm{H}$, singlet $), 0.90(3 \mathrm{H}$, singlet $), 1.13(3 \mathrm{H}$, doublet, $J=6 \mathrm{cps}), 1.90$ (1H, singlet).

Dihydro-diacetate (4), Tetrahydro-diacetate $(24.0$ $\mathrm{mg}$ ) thus obtained was dissolved in pyridine $(3 \mathrm{ml})$ and added portionwise to the solution of chromium trioxide $(100 \mathrm{mg})$ in pyridine $(1 \mathrm{ml})$. The reaction mixture was kept standing overnight at room temperature and extracted with benzene. Then, the extract was washed with dil. $\mathrm{HCl}$ and water, and was evaporated to give a dark residue. The residue was purified by preparative TLC with the solvent system of A. The zone at $R f 0.53$ was extracted with chloroform. Evaporation of the solvent gave oily dihydrodiacetate $4(21.1 \mathrm{mg}) . \quad \mathrm{C}_{25} \mathrm{H}_{38} \mathrm{O}_{5},[\alpha]_{\mathrm{D}}^{25} 46.1^{\circ} \quad(c=2.31$, $\left.\mathrm{CHCl}_{3}\right) ; \mathrm{IR} \nu_{\max }^{\mathrm{Film}} \mathrm{cm}^{-1}: 1740,1705,1360,1250,1030$; MS m/e: 418, 358, 343, 298 (base peak), 283, 273, $265,255,240,228,213$; NMR $\delta: 0.61$, (3H, singlet), $0.88(3 \mathrm{H}$, singlet), $2.00(6 \mathrm{H}$, singlet), $2.15(3 \mathrm{H}$, singlet), $4.65(2 \mathrm{H}$, broad multiplet).

Saponification of dihydro-diacetate (4) to dihydrodiol (5). Dihydro-diacetate 4 (46.0 mg) was dissolved in $5 \% \mathrm{KOH}$ in methanol $(5 \mathrm{ml})$ and kept standing at room temperature for $30 \mathrm{~min}$. The reaction mixture was diluted with water and extracted with ethyl acetate. The extract was washed with dil. $\mathrm{HCl}$ and water, and evaporated. The dark residue was purified with preparative TLC using the solvent system of $\mathrm{D}$. The zone at $R f 0.33$ was extracted with chloroform. Evaporation of the solvent gave a colorless powder $(25.2$ mg). mp $184 \sim 185^{\circ} \mathrm{C} ; \quad[\alpha]_{\mathrm{L} ;}^{25} \quad 50.7^{\circ} \quad(c=1.26) ; \quad$ IR $\nu_{\mathrm{max}}^{\mathrm{Nujol}} \mathrm{cm}^{-1}: \quad 3250,1700,1375,1040 ;$ MS m/e; 334, 316 (base peak), 301, 298, 283, 273, 258, 246, 231, 213; NMR $\delta: 0.61(3 \mathrm{H}$, singlet), $0.81(3 \mathrm{H}$, singlet $), 2.01$ ( $3 \mathrm{H}$, singlet), $2.43(2 \mathrm{H}$, broad singlet $), 3.43(2 \mathrm{H}$, broad multiplet).

2,4-Dinitrophenylhydrazone of dihydro-diol (5). 2,4- 
Dinitrophenylhydrazine $(50 \mathrm{mg})$ was dissolved in $95 \%$ ethanol $(3 \mathrm{ml})$ to which a drop of conc. $\mathrm{HCl}$ had been added. To the solution thus obtained was added dihydro-diol $5(25.2 \mathrm{mg})$ dissolved in $95 \%$ ethanol ( $1 \mathrm{ml}$ ). After standing for $10 \mathrm{~min}$ at room temperature, the reaction mixture filtered to separate the product. Several recrystallization from ethanol gave the desired hydrazone $(60 \mathrm{mg})$. $\mathrm{mp} 260 \sim 261.5^{\circ} \mathrm{C}$ (decomp.); IR $\psi_{\max }^{\mathrm{xujol}} \mathrm{cm}^{-1}$ : 3340, 1620, 1595, 1340, $1310,1040,918,840,740$; MS m/e: 514, 484, 461, 453, 450, 439, 422, 332, 316, 299, 257 (base peak);

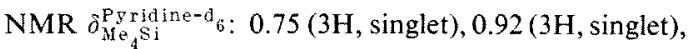
2.01 (3H, singlet), 2.45 ( $2 \mathrm{H}$, multiplet), $3.00(1 \mathrm{H}$, multiplet), 3.60 (1H, singlet), 5.10 (3H, multiplet), $8.00(1 \mathrm{H}$, doublet, $J=10 \mathrm{cps}), 8.40(1 \mathrm{H}$, quartet, $J=$ 10 and 2.5 cps).

The Brown borohydration of 2,4-dinitrophenylhydrazone of pregnenolone. 2,4-Dinitrophenylhydrazine $(1.6 \mathrm{~g})$ was dissolved in $95 \%$ ethanol $(30 \mathrm{ml})$, to which water $(10 \mathrm{ml})$ and conc. $\mathrm{H}_{2} \mathrm{SO}_{4}(6 \mathrm{ml})$ were added. To this solution was added pregnenolone $(2 \mathrm{~g})$ dissolved in methanol $(6 \mathrm{ml})$. After standing for $1 \mathrm{hr}$ at room temperature, the reaction mixture was filtered to separate the product. Several recrystallization from ethanol gave the hydrazone $(2.58 \mathrm{~g})$. mp $251 \sim 253^{\circ} \mathrm{C}$ (decomp.); IR : $: \mathrm{max}_{\mathrm{mal}} \mathrm{cm}^{-1}: 3610,3320,1620,1595$, $1340,1318,840,740$.

2,4-Dinitrophenylhydrazone of pregnenolone $(2 \mathrm{~g})$ thus obtained was dissolved in tetrahydrofuran $(150 \mathrm{ml})$ under nitrogen, and was added a solution of $c a .1 \mathrm{M}$ diborane in diglyme $(200 \mathrm{ml})$. After standing for $1 \mathrm{hr}$ at room temperature, the reaction mixture was added with water $(5 \mathrm{ml})$ and heated to $45^{\circ} \mathrm{C}$. Aqueous $10 \% \mathrm{NaOH}(35 \mathrm{ml})$ and $30 \% \mathrm{H}_{2} \mathrm{O}_{2}$ solution $(80 \mathrm{ml})$ were added there, and the reaction mixture was stirred for an additional $1 \mathrm{hr}$ at $45^{\circ} \mathrm{C}$. Then, the mixture was diluted with water and extracted several times with chloroform. The combined extracts were dried and evaporated to give the desired 2,4-dinitrophenylhydra. zone $(1.4 \mathrm{~g})$. Recrystallization from methanol gave the analytical sample. Mp, IR, NMR, and mass spectra were identical with those of 2,4-dinitrophenylhydrazone of dihydro-diol (5).

Acknowledgements. We wish to thank Prof. Y. Hashimoto of the University of Tokyo and Prof. T. Yasumoto of Tohoku University for their kind supply of asterosaponins. We are also grateful to Mr. K. Ajzawa and his staff of this Department for measurements or IR, UV, NMR and mass spectra.

\section{REFERENCES}

1) Y. Hashimoto and T. Yasumoto, Bull. Jap. Soc. Sci. Fisheries, 26, 1132 (1960).

2) T. Yasumoto, T. Watanabe and Y. Hashimoto, Bull. Jap. Soc. Sci. Fisheries, 30, 357 (1964).

3) T. Yasumoto and Y. Hashimoto, Agr. Biol. Chem., 29, 804 (1965); idem, ibid., 31, 368 (1967).

4) E. L. Eliel, "Stereochemistry of Carbon Compounds," McGraw-Hill Book Co., New York, N. Y., 1962, pp. 416 422.

5) J. N. Shoolery and M. T. Rogers, J. Am. Chem. Soc., 80, 5121 (1958).

6) R. F. Zürcher, Helv. Chim. Acta, 44, 1380 (1961); idem, ibid., 46, 2054 (1963).

7) S. Wolfe, M. Nussim, Y. Mazur and F. Sondheimer, J. Org. Chem., 24, 1034 (1959).

8) A. B. Turner, D. S. H. Smith and A. M. Mackie, Nature, 233, 209 (1971).

9) A. M. Mackie, R. Lasker and R. T. Grant, Comp. Biochem. Physiol., 26, 415 (1968). 